Case report

\title{
Farber's disease (lysosomal acid ceramidase deficiency)
}

\author{
R A JAMESON, P J L HOLT, AND J H KEEN \\ From Booth Hall Children's Hospital, Manchester
}

SUMMARY The patient presented with progressive joint deformity, a hoarse voice, subsequent cachexia, and myoclonic seizures. She was first seen aged 22 months and died aged 6 years. A diagnosis of Farber's disease was made by demonstrating a deficiency of acid ceramidase both in leucocytes and fibroblasts.

Key words: arthritis, juvenile.

\section{Case report}

The patient, a female Caucasian child, was born at term after an uneventful pregnancy and weighed 3.0 $\mathrm{kg}$ (25th centile). She was the second child born to unrelated parents. There was no relevant family history.

Her growth and development had been unremarkable until 8 months of age. She then became irritable, had difficulty rolling over, and was reluctant to crawl, stand, or walk.

Examination when first seen (aged 22 months) showed her height and weight to be between the 25 th and 50th centile. She had a husky voice, which persisted. At laryngoscopy (Mr Devine) the vocal cords moved normally and no local pathology was seen, the hoarse voice being attributed to laryngomalacia. There were obvious joint abnormalities. There was firm swelling of all distal interphalangeal, proximal interphalangeal, and metacarpophalangeal joints with flexor tendon nodules in the palms, resulting in reduced finger extension. Both elbows lacked $20^{\circ}$ extension but were not swollen. There were bilateral dorsal wrist swellings, but the wrist movements were virtually normal. Her knees had periarticular thickening and their extension was limited by $20-30^{\circ}$. She had tender and slightly swollen toes, but joint tenderness was otherwise not obvious. Other joints were

Accepted for publication 16 December 1986.

Correspondence to Dr J H Keen. Booth Hall Children's Hospital. Charlestown Road, Blackley. Manchester M9 2AA. normal (Fig. 1a). There was no hepatosplenomegaly, lymphadenopathy, or rash.

Full examination of her eyes, including the anterior chambers and fundi, was normal (Mr Dodd).

A diagnosis of juvenile arthritis was made and she was treated with ibuprofen penicillamine, and splinting of the knees.

Over the following three years despite the use of local steroids and systemic prednisolone to a maximum of $12.5 \mathrm{mg} /$ day her joint problems progressed with only brief periods of improved function. At the best she could stand and take a few steps in a frame. Muscle development was always poor and terminally extreme muscle wasting was seen. She developed nodules of the tendon sheaths and joint capsules in the hands. At the age of 4 years she developed brief myoclonic seizures. These became more persistent, resulting in minor status epilepticus. Various anticonvulsants had only short term effects in controlling the seizures. She had marked growth failure, her weight not having increased from 15 months until her death at 6 years of age. She became totally deaf in the right ear with a mixed hearing loss on the left. By the age of 6 years she had limited movement of her shoulders, marked flexion deformity of elbows, hands, hips, knees, and feet with marked muscle wasting. Her reflexes, however, were normal.

Her condition continued to deteriorate with increasing feeding and respiratory difficulties and intermittent fever. She died aged 6 years and 2 

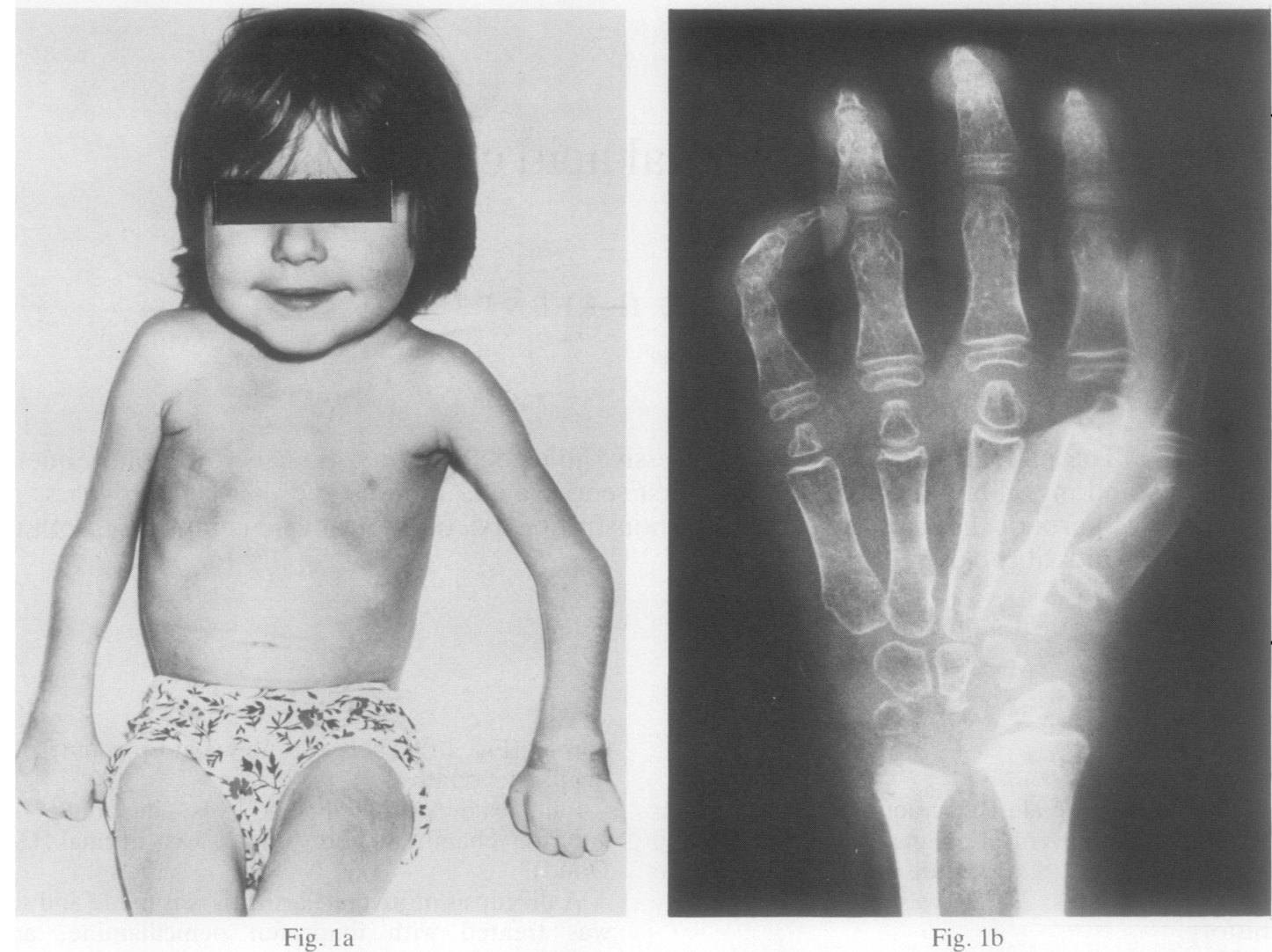

Fig. 1 (a) Patient aged 5 years, showing some joint deformities. (b) X ray of the left hand of the patient aged 5 years, showing osteopenia, flexion of the fingers, defective epiphyseal development, and underdevelopment of the terminal phalanges.

months with a respiratory infection. Unfortunately a postmortem examination was refused.

\section{N V E S T I G A T I O N S}

She was psychologically assessed (Mrs V Mellor) at intervals throughout her life, and at 4 years 2 months of age her intelligence quotient was 63 as measured by the Merrill Palmer scale. The Vineland social maturity scale gave her an age equivalent of $2 \cdot 3$ years. Her musculoskeletal problem only partly contributed to this low score.

The following investigations were negative: thyroid function tests (tri-iodothyronine, thyroxine, thyroid stimulating hormone), antinuclear factor test, double stranded deoxyribose nucleic acid antibody titres. Antibodies to parietal cells, mitochondria, smooth muscle, and reticulin were also negative. Serum immunoglobulins were normal. Erythrocyte sedimentation rate (Westergren) varied between 8 and $47 \mathrm{~mm}$ in one hour. The $C$ reactiveo protein was positive.

At 4 years of age the cerebral computed tomo-ᄋ graphic scan was normal, but the electroencephalo $\rightarrow$ gram aged 6 years showed generalised frequen?르. irregular episodes of paroxysmal sharp and slow wave activity compatible with a severe generalise ${ }^{\curvearrowright}$ seizure disorder.

At 6 years of age her chest $x$ ray and screening of the diaphragm showed paralysis of the right side suggesting a right phrenic nerve palsy. There waso generalised osteopenia with reduced diameter of long bones, growth arrest lines (Harris lines), and? poor muscular development. The serial radiographso showed increasing flexion of fingers and toes and? eventually subluxation. Rotation of the carpus and volar dislocation was associated with Madelung'这 deformity. Epiphyseal development of the phalanges was defective and the terminal phalanges were 
Table 1 Estimation of acid ceramidase levels in white cells and fibroblasts*

\begin{tabular}{lll}
\hline & Acid ceramidase & Arylsulphatase A \\
\hline White cells & & $79 \cdot 3$ \\
Patient & $0 \cdot 022$ & 117 \\
Control & $4 \cdot 39$ & 124 \\
Control & $3 \cdot 37$ & \\
& & - \\
Fibroblasts & $0 \cdot 002$ & - \\
Patient & $0 \cdot 083$ & - \\
Control & $0 \cdot 087$ & \\
Control & & \\
\hline
\end{tabular}

${ }^{*}$ Values are given as $\mathrm{nmol} / \mathrm{h} / \mathrm{mg}$ protein.

undeveloped (Fig. 1b). The acetabular roofs were hypoplastic and there was an increased angle between the shafts and heads of the femora (coxa vara). The iliac bones were very vertical. The reason for these changes is not clear. Other features noted were squaring of vertebrae and narrow discs, normal ribs and clavicle.

SPECIAL INVESTIGATIONS

Acid ceramidase levels in white cells and fibroblasts were estimated (Dr Fensome) in leucocytes using $\left[{ }^{14} \mathrm{C}\right]$ palmitoyl sphingosine as a substrate and arylsulphatase $A$ as a reference enzyme. The results indicate a marked deficiency of acid ceramidase (Table 1).

The typical history together with the low levels of cellular acid ceramidase are diagnostic of Farber's disease.

\section{Discussion}

Farber first described this disorder in $1957 .{ }^{1}$ It is a rare progressive disorder associated with deficiency of lysosomal acid ceramidase and has been described in some detail by Moser and Chen, ${ }^{2}$ who found descriptions of only 27 children in the literature. Inheritance is of autosomal recessive character.

The usual onset is before the age of 1 year. Characteristic features include painful, deformed joints, in particular, proximal and distal interphalangeal and metacarpal joints, wrist, elbow, knee, ankle, and metatarsals. Suggestive features include a hoarse voice, subcutaneous nodules, feeding and respiratory difficulties, poor weight gain, and intermittent fever. All of these occurred in our patient. Glossal enlargement and hepatosplenomegaly were not seen, however, unlike the cases described by Toppet et al. ${ }^{3}$

The neurological degeneration seen in this child is less frequently found. Moser and Chen found that 10 out of 27 reported children had severe progressive impairment of psychomotor development. Only two had salaam type seizures. Twelve had evidence of peripheral nerve involvement. This child therefore is the only case reported with progressive myoclonic seizures and minor status epilepticus.

There is no specific therapy for Farber's disease. Diagnosis is important. It is an autosomal recessive condition. Heterozygotes have intermediate levels of lysosomal acid ceramidase. Antenatal diagnosis is possible using cultured skin cells from the amniotic fluid to assay the acid ceramidase, making possible the selective abortion of affected fetuses.

We would like to express our gratitude for advice and encouragement from Dr Barbara Ansell and Dr Ian McKinlay. The fibroblast and white cell ceramidase studies were carried out by $\mathrm{Dr} \mathrm{A} \mathrm{H}$ Fensome, principal biochemist, Guy`s Hospital, London.

\section{References}

1 Farber S, Cohen J, Uzman L L. Lipogranulomatosis. A new lipoglycoprotein 'storage' disease. Journal of the Mount Sinai Hospital 1957; 24: 816-37.

2 Moser H W. Chen W W. Ceramidase deficiency. Farber's lipogranulomatosis. The metabolic basis of inherited disease. 5th ed. New York: McGraw-Hill, 1983: 820-30.

3 M Toppet, Vamos-Hurwitz E. Jonniaux G. Cremer N, Tondeur M, Pelc S. Farber's disease as a ceramidosis: clinical, radiological and biochemical aspects. Acta Paediatric Scand 1978; 67: $113-9$ 